\title{
Evaluation of the Activity of Insecticides Plants in the Far North Region of Cameroon
}

\author{
Sadou Ismaël ${ }^{1}$,Woin Noé2 ${ }^{2}$ Ghogomu Richard ${ }^{3}$, Mbongaya Samy Eware ${ }^{4}$ \\ ${ }^{1}$ Head of Regional Centre for Research and Innovation in Far North of Cameroon, Maroua, Cameroon. \\ ${ }^{2}$ General Manager of the Institute of Agricultural Research for Development, Yaoundé, Cameroon. \\ ${ }^{3}$ Faculty of Agronomyand Agricultural Sciences, University of Dschang, Cameroon. \\ ${ }^{4}$ The Higher Institute of the Sahel, University of Maroua, Cameroon.
}

\begin{abstract}
This study proposes to assess the activity of insecticide plants in the far North region of Cameroon. The leaves or bark of four local plants (Azadirachtaindica, Boswelliadalzeilii, Khayasenegalensis and Ocimumcanum) were harvested, dried and powdered for the formulation of insecticidal chopsticks at different doses. Toxicity tests have been conducted on adult culicidae mosquitoes by fumigation. They reveal low levels of mortality after 15 minutes of exposure to the smoke of the chopsticks. Remanence due to chopsticks smoke leads to high rates of mortality after 6 and 24 hours of exposure. Mortality rates increase with the dose of each vegetable powder. Lethal doses were calculated 6 hours after exposure for each plant powder. Those of the leaves of Azadirachtaindica proved to be the most efficient thus with the lowest LD50 value of $36.14 \%$. These vegetable powders can be used as natural insecticides instead of chemical insecticides.
\end{abstract}

Keywords - Insecticides, Culicidae adult, fumigation, mortality, remanence rate, lethal dose.

\section{INTRODUCTION}

Insects form an important group of animal in ecosystem. Some are useful (sources of food, pollinators and Entomophagous) others are harmful (insect pests of plants or vectors of diseases). Insects can also be vectors of diseases to man it the case of mosquitoes and many others. Mosquitoes are insects of the order diptera. The family of culicidae are the most important, includes three species mainly pathogenic for man: the anopheles, aedes and culex. Anopheles are scare in temperate zone and they are undoutable especially in tropical countries thus are vectors of malaria (Slip et al., 2006). It's a parasitic disease of waterborne origin which continues to pose a problem to public health (Brahimand et al., 2006).

In anti-mosquito campaign fight, the active ingredients of the insecticides used belong to the organophosphates, pyrethroids and carbamates synthesis (Brahimand et al., 2006). These preparations, although they are proved to be very effective on mosquitoes culicidae, have several drawbacks. Indeed, in addition to their high cost, they can be at the origin of various environmental problems. The significant accumulation of active ingredients of insecticides of synthesis in aquatic and terrestrial ecosystems cause a problem of pollution (Barbouche et al., 2001). Moreover, the active substances of the products used have a broad spectrum of action and does not eliminate non-target organisms. All these disadvantages added is also a big problem of development of resistance to chemical insecticides, by insect treated (Georghiou et al., 1975; Sasmalet al., 1977).

To ensure a better response, while maximally preserving the environment, new alternatives are more encouraged. Natural substances that present a broad spectrum of Pharmacology action can be used as alternative insecticides for replacement, the use of extracts of plants as insecticides is known is known since. According to Jacobson (1989), more than 2000 plant species possess an insecticidal activity have already been identified. In fact nicotine, pyrethrum and rotenone are already known as control agents against insects (Crosby, 1966). In parts of black Africa, tobacco mixed in water leaves were used to combat mosquitoes.

In Cameroon, the work of Saotoing (2005), confirm the insecticidal effect of the essential oil extracted from the leaves of Ocimum Canum (Basil of small leaves) and several other local plants on adult mosquitoes. To follow this idea of local Herbal insect control, we propose to assess the activity of insecticides on some plants in the far North region of Cameroon.

To achieve this, mosquito larvae will be harvested and breed for adult mosquitoes, and then insecticides chopsticks will be formulated based on plant powders of the following plants: leaves of Ocimum canum and Azadirachta indica, bark of Khaya senegalensis, the leaves and the bark of Boswellia dalzielii. Finally, we will assess the insecticidal activity of these chopsticks on adult mosquitoes by fumigation.

\section{MATERIALS AND METHODS}

Presentations of the study area 
The chief town of the far - North Region of Cameroon (Maroua) is our main study area. It is located at an altitude of 400 meters, in the savannah region. We note characteristic presence of plants such as Anogeissus leocarpus on soft and non-cleared soil and Boswellia dalzielii on stony soil and Balanites aegyptiaca (Barbouche et al., 2001).

\section{Harvest and breeding of Culicidae}

\section{1 - Larva specimens.}

The larvae were harvested in the town of Maroua for the months of June and July 2011. Several stagnant (gite) water was systematically examined to have a diversity of culicidae.

The larvae are marked by their horizontal position on the surface of the cottage. They are collected from their roosts using a ladle and introduced in boxes with water from the cottage to be transported to the laboratory of the Institute of agricultural research for development where they will be breed. Once in the laboratory larvae are transferred into a plastic basin where they are kept in natural conditions for breeding with water of different deposit.

\section{2 - Breeding of Culicidae}

Larvae collected directly from deposits are transferred in small basins with a few pinches of nutritional powder (powder shrimp + biscuits) for 2 to 3 days each morning. Every day the water from the basins is replaced by spring water. Replacement of source water is to prevent pollution resulting from the presence of powder nutrient. Two to three days after the introduction of the larvae in the basins, larvae have been transformed into nymphs. Then nymphs removed from basins are transferred to plastic glasses using a micropipette. Glasses containing nymphs were placed inside the cages made of canvas's mosquito net of about $8200 \mathrm{~cm}^{3}$ in volume. In each cage, is placed a plate containing moistened cotton of sweet juice made from sucrose $10 \%$, providing food for adult mosquitoes. At the emergence within the cages, adult mosquitoes can feed before being submitted to toxicity tests.

\section{Preparation of plant material}

The plant material is made of leaves of (Ocimum canum, Azadirachta indica) and bark of Khaya senegalensis, leaves and bark of Boswellia dalzielii.

\section{1 - Harvesting and drying of the leaves and bark}

Green leaves (Ocimum canum as well as of Azadirachta indica) and the bark of Khaya senegalensis and Boswellia dalzielii are collected and introduced in a bag. They are then dried in the shade in order to keep the active ingredient they contain. Indeed, the active ingredient very often volatile evaporates in the presence of heat (Brey, 2005). Every day, we pass hand to expose all sheets at room temperature in order to avoid that those below are either not well dried. Similarly, to ensure complete drying of the bark, they are returned from time to time to expose www.ijeab.com both sides at room temperature. Bark drying requires about ten days. As for the leaves, after 5 to 6 days of drying, they can crumble by friction: they are then ready for the preparation of plant powder.

\section{2.-Preparation of the vegetable powder}

The dried leaves of the selected plants are powdered. The barks are powdered with a scraper in aluminum.

Obtained plant powders constitute base product for the manufacture of many types of insecticides which formulation varies depending on the type of use or even the type of target insect.

\section{3.-Formulation of the insecticide strips}

Insecticides are formulated from plant powders (bark or leaves). For each insecticide formulated, vegetable powder is the active ingredient. In order to vary the percentage of active ingredient, a witness powder was used. The choice of the indicator must meet a number of conditions: it must not present insecticidal activity, it must allow the plant material to form a paste, it should burn enough.

For each vegetable powder, five different percentages in plant material sticks are formulated. These percentages are: $15 \%, 30 \%, 45 \%, 60 \%$ and $75 \%$. For each percentage dry matter (vegetable powder + witness) Mtotal mass was set at 4 grams to $3 \mathrm{ml}$ of water approximately. The masses of vegetable powder and powder witness are measured using an electronic scale of brand Lutron having the features GM-300, $300.00 \mathrm{~g} \mathrm{0,} 01 \mathrm{~g}$.

For a baguette containing $\mathrm{x} \%$ of plant material, a mass $\mathrm{M}$ of plant material was measured as:

$$
M=\frac{M_{\text {Totde }} \times x}{100}=\frac{4 x}{100}
$$

For the conduct of the sinkers, the following steps have been respected:

- On the balance and make sure using the water level that it is positioned horizontally on the bench. The balance then mark $0.00 \mathrm{~g}$

- Place a sheet of paper considered here as the tare weight on the scale. The balance will then mark the mass of the sheet of paper.

- Press on the "tare" button on balance to cancel the mass of the sheet of paper and bring balance to $0.00 \mathrm{~g}$

- Gradually collect plant material using the spatula and place on the sheet of paper asked on the scale until it mark the mass $\mathrm{M}$ corresponding to the dose $\mathrm{x} \%$ reporting.

- Complete plant material located on the balance by the witness powder until it marks the mass Mtotal $=4.00 \mathrm{~g}$

The corresponding indicator MT mass is obtained by making the following difference: 


$$
M_{\text {Témoin }}=M_{\text {totale }}-M=4-M
$$

For each percentage, the measured masses of plant material and witness are introduced into a Petri dish and homogenized box. Using a syringe, $3 \mathrm{ml}$ of water is added to this mixture and homogenized again.

The resulting mixture is introduced into a cylindrical mould. Out of the mold, we obtain a wet cylindrical chopsticks. Each chopsticksis label. A label of chopsticks bears the name of the plant, its extract to be used and the corresponding percentage of plant material. After a two (02) days of drying in the shade, the chopsticks are ready to be inflamed and produce smoke for toxicity testing.

\section{4 - Toxicity tests}

To increase the credibility of toxicity tests, preliminary experiments were conducted to determine the optimal witness powder and the average lifespan of the culicidae in breeding conditions of the laboratory.

\section{1-Preliminary experiments}

\subsection{1. - Choice of the witness powder}

Chopsticks have been realized with two different witness powders namely corn powder and powder of the tubers of cassava (starch). The objective is to determine which of the two powders has the following advantages:

- Insecticide effect near zero

- Capacity of adhesion with vegetable powder with water

- Slow consumption.

4.1.2-Choosing the age of adult culicidae subjected to toxicity test

At the adult State, the culicidae can still live one to several weeks in their natural environment. The life expectancy of the adult culicidae was evaluated. This evaluation was conducted in the breeding conditions of the laboratory. We note that 3 to 4 days after emergence in adulthood, mosquitoes die. Considering this reality of

laboratory, we opted to perform tests on the culicidae between the first and the second day after their emergence in adulthood.

4.2.-Putting into evidence the insecticide effect of the chopsticks on the adult culicidae.

Toxicity tests are performed on the adult culicidae by the method of fumigation. This method is to ignite an insecticide stick near studied insects. The flaming sticks burn producing smoke whose effect on insects will translate its insecticide activity or not.

Insecticide strips made are inflamed and placed on a support, and introduced in the cages each containing 50 mosquitoes.

Each cage of mosquito is exposed to smoke from insecticide stick for 15 minutes.

The "knock-down" effect is observed and appreciated on mosquitoes after three minutes for each dose and for each plant powder.

The fifteenth minute of exposure, the insecticide chopsticks are removed from the cage and first killed mosquito count is done. Six hours and 24 hours later, a second count and a third count are performed.

The different results are carefully noted for later use in the calculation of the rates of mortality and the determination of the LD50.

\section{5 - Statistical analysis}

5.1-Calculation of the rate of mortality of adult mosquitoes

It is important to check the initial population of the living adult mosquitoes before any experience. In fact, it can happen that mosquitoes are already dead before the start of the experiment, or that all nymphs caged did not emerge in adulthood. This check allows you to redefine the adult mosquito population initially fixed at 50 per cage. We can then calculate the rate of mortality $\mathrm{T}$ according to formula:

$$
T=\frac{\text { Numbers of mosquitos' death during experience }}{\text { Numbers of life mosquitoes before experiment }} \times 100
$$

\section{2.-determination of the lethal dose 50 (DL50)}

For each vegetable powder, the dose that led to a $50 \%$ mortality of adult mosquitoes is the DL50. It is represented by the regression equation expressing the rate of mortality as a function of different doses for each plant powder.

$y=a x+b$

$y$ : Rate of mortality (in \%)

$x$ : Consider dosage of plant mater (in \%)

The determination of LD50 values enable to make a comparative study of the effectiveness of the studied plant powders, indeed the most effective plant powder is the one that has the lowest LD50 that is those presenting insecticide effect at lower dose.

\section{RESULTS AND DISCUSSIONS}

At the end of the work in the laboratory, we manufactured insecticides chopsticks made from powders of some plants in the region of the far North Cameroon. These tubs were made at different doses. To assess the insecticidal activity of these sticks, we harvested and breed mosquito larvae for adult mosquitoes on which we carried out fumigation toxicity tests.

\section{1-Insecticides tub and control tub}

We observe that the two powders have no insecticidal effect, adhesion of starch in the presence of water is satisfactory compared to corn powder, corn powder 
consumption is faster, which reduces the time of exposure to mosquitoes.

At the end of this experience, cassava powder stands as the effective witness for toxicity tests.

For each selected vegetable powder, five different percentages in plant material sticks are formulated. These percentages are: $15 \%, 30 \%, 45 \%, 60 \%$ and $75 \%$. For each percentage, we set the mass $M$ Total of dry matter (vegetable powder + witness) at 4 grams for $3 \mathrm{ml}$ of water approximately.

Table 1 shows the masses of vegetable matter and control powder by dose of tub.

Table.1: Masses of vegetable matter and powder control by dose of tub

\begin{tabular}{lllllll}
\hline \multicolumn{1}{c}{ Doses } & $15 \%$ & $30 \%$ & $45 \%$ & $60 \%$ & $75 \%$ & Témoin \\
$\begin{array}{l}\text { Masses } \\
\begin{array}{l}\text { Mass of powder plants } \\
M(g)\end{array}\end{array}$ & 0,6 & 1,2 & 1,8 & 2,4 & 3,0 & 0,0 \\
\hline $\begin{array}{l}\text { Mass of control of } \\
\text { powder } M_{\text {control }}(g)\end{array}$ & 3,4 & 2,8 & 2,2 & 1,6 & 1,0 & 4,0 \\
\hline \begin{tabular}{l} 
Total Mass $M_{\text {Total }}(g)$ \\
\hline
\end{tabular} & 4,0 & 4,0 & 4,0 & 4,0 & 4,0 & 4,0 \\
\hline
\end{tabular}

The insecticide tub obtained after drying in the shade is compact and fragile depending on dosages of powder used for each plant. Chopsticks at low doses are less fragile than those with high doses. Chopsticks color also varies with dose: low dose of plant powder, the tub seems clearer.

\section{2-Evaluation of insecticidal activity of chopsticks.}

\section{1-Test using the control tub}

The witness test is performed using the control tub incorporated mass $0 \%$ vegetable powder and $100 \%$ of starch powder. The action smoke from the control tub causes agitation of mosquitoes without all times knock them out.

\subsection{1-Variation in the rate of mortality for 15 minutes of exposure}

The variation of mortality 15 minutes after exposure of adult mosquitoes at different doses of five plant powders is represented in figure 1.

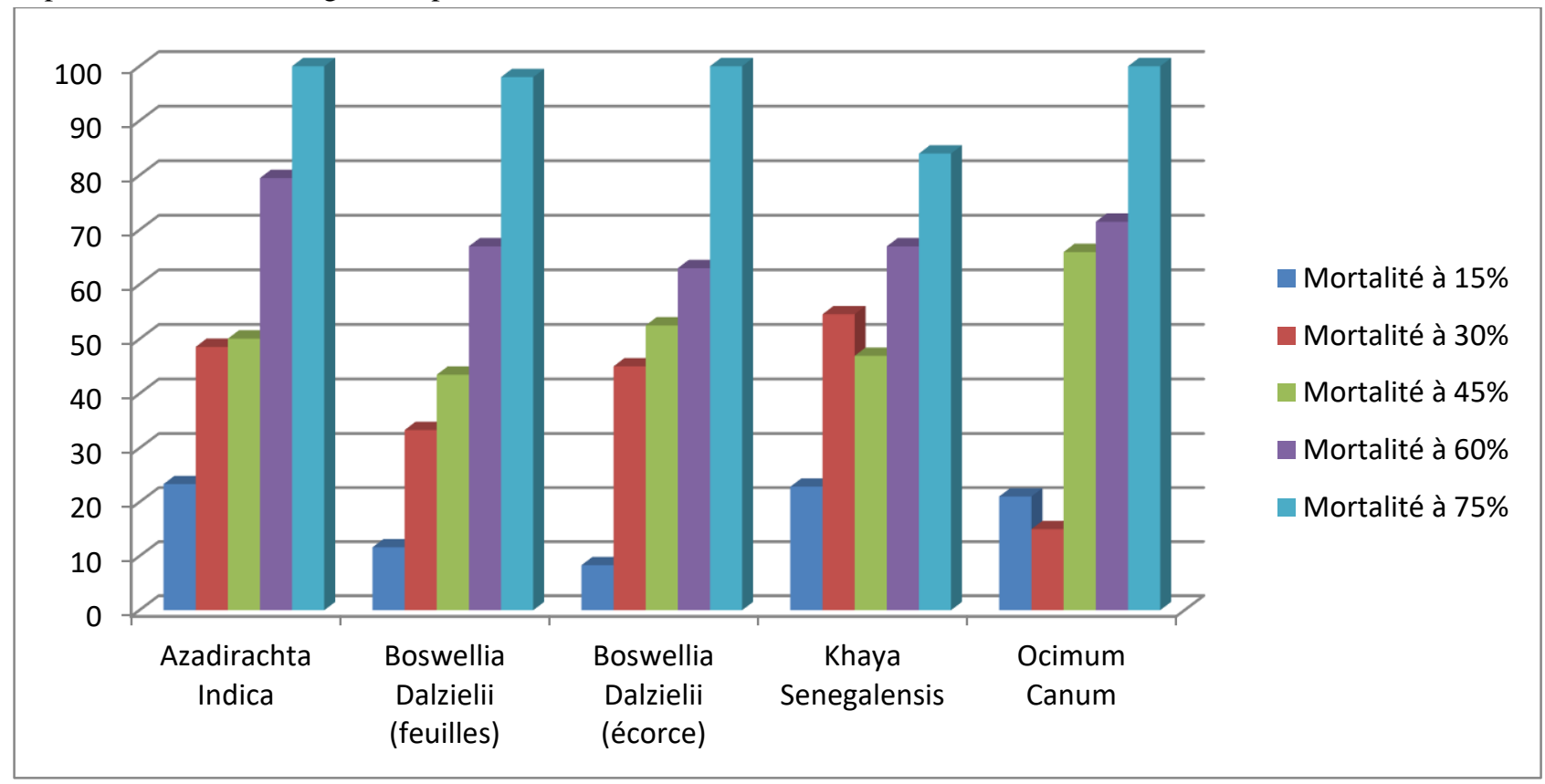

Fig.1: Mortality of mosquitoes depending on the dose of the plant powder for four species of plant after 15 minutes of exposure

The figure 1shows that after exposing adult mosquitoes at different doses of five plant powders for 15 minutes, the actual insecticidal effect is observed. The mortality rate is quite low and increases with the dose for each vegetable powder (table 2). 
Table.2: Mortality of mosquitoes depending on the dose of the powder plant for four plant species after 15 minutes of exposure

\begin{tabular}{ccccccc}
\hline \multicolumn{1}{c}{ Doses } & $15 \%$ & $30 \%$ & $45 \%$ & $60 \%$ & $75 \%$ & Témoin \\
Plantes & & & & & & \\
\hline Azadirachta indica & $8,57 \pm$ & $13,33 \pm$ & $18,18 \pm$ & $20,5 \pm$ & $28 \pm 2,56$ & 0 \\
(leaves) & 3,10 & 3,77 & 2,68 & 2,46 & & \\
\hline Boswellia dalzielii & $4,65 \pm$ & $13,33 \pm$ & $15,22 \pm$ & $16,27 \pm$ & $17,36 \pm$ & 0 \\
(leaves) & 2,43 & 8,88 & 2,50 & 2,35 & 2,24 & \\
\hline Boswellia dalzielii & $5,87 \pm$ & 14,01 & $17,50 \pm$ & $17,5 \pm$ & $18 \pm 2,36$ & 0 \\
(bark) & 6,50 & & 2,93 & 2,29 & & \\
\hline Khaya senegalensis & $5,71 \pm$ & $9,18 \pm$ & $18,37 \pm$ & $19,01 \pm$ & $22 \pm 2,20$ & 0 \\
(bark) & 3,02 & 10,74 & 2,41 & 2,28 & & \\
\hline Ocimum canum & $10,00 \pm$ & $13,15 \pm$ & $19,15 \pm$ & $21 \pm 2,32$ & $23,40 \pm$ & 0 \\
(leaves) & 2,75 & 2,97 & 2,53 & & 2,40 & \\
\hline
\end{tabular}

At lower doses $15-30 \%$ Ocimum canum presents higher mortality rates of 10 and $13,15 \%$ respectively. For high doses $60 \%$ and $75 \%$, Azadirachta indica is the insecticide with the mortality rate of 20.5 and $28 \%$ respectively. In all of these results, a first classification of toxic efficacy on tested vegetable powders is highlighted, thus the most toxic plant powders are those of the leaves of Azadirachta indica and Ocimum canum. The least toxic of the leaves is Boswellia dalzielii.

2.1.2-Variation in rate of mortality 6 hours after exposure to mosquitoes

The variation of mortality 6 hours after exposure of adult mosquitoes at different doses of five plant powders is represented in figure 2 .

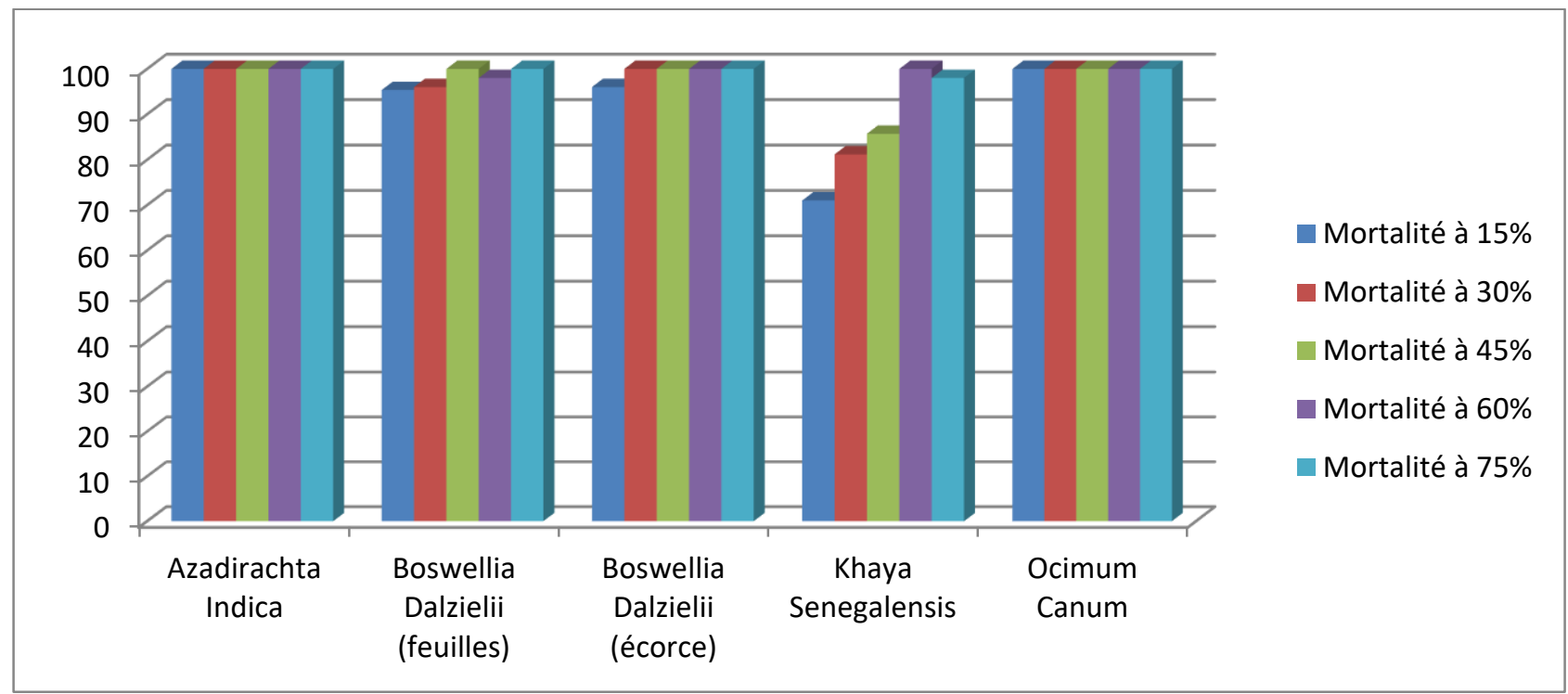

Fig.2: Mortality of mosquitoes depending on the dose of the plant powder for four species of plant 6 hours after exposure

The figure 2 shows that six hours after the exposure of the mosquitoes, the insecticide effect is accentuated. The mortality rate also increases with the dose for each plant powder.

At low doses $15-30 \%$ bark of Khaya senegalensis have the highest mortality rates 22.86 and $54.55 \%$ respectively. For high doses $60 \%$ and $75 \%$, Azadirachta indica is the highest insecticide with the mortality rate of 79.51 and $100 \%$, respectively. In all of these results a second identical classification to the first classification (figure 2).
On effectiveness of toxic plant powders tested is highlighted, thus the most toxic plant powders are those of the leaves of Azadirachta indica and Ocimum canum. The less toxic is leaves Boswellia dalzielii.

\subsection{3-Variation in the rate of mortality 24 hours after} exposure

The variation in mortality rate 24 hours after exposure of adult mosquitoes at different doses of five plant powders is represented in figure 3 . 


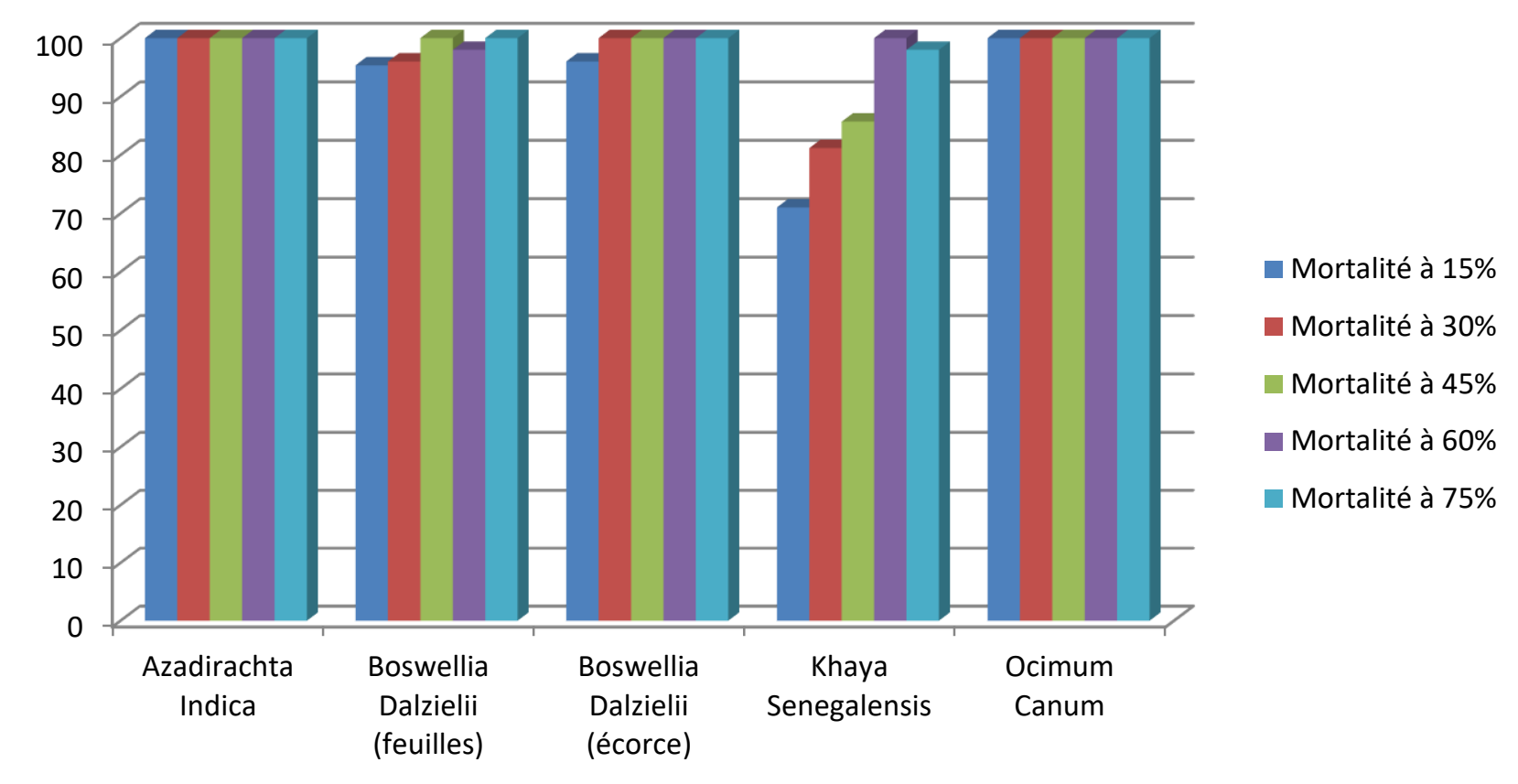

Fig.3: Mortality of mosquitoes depending on the dose of the plant powder for four species of plant after 24 hours of exposure.

The figure 3 shows that the mortality rate is high among all vegetable powders and varies depending on the dose. In plant powders of Azadirachta indica with Ocimum canum, mortality is capped at $100 \%$ from the $15 \%$ dose. In all of these results a classification of effectiveness of toxic powders tested is highlighted, so the most toxic powders are those of the leaves with mortality rates highest namely 10 and $13,15 \%$ respectively of Azadirachta indica with Ocimum canum and least toxic is the leaves of. Boswellia dalzielii.

\section{2-Assessment of the LD50 (lethal dose 50)}

The determination of the lethal dose of each vegetable powder that causes $50 \%$ of mortality in adult mosquitoes was made from the regression line representing (expressed as a percentage) mortality rates according to the doses of these powders.

Table 3 represents the regression equation, correlation coefficient, and LD50 values obtained for different plant powders.

Table.3: Different LD50 of powder plant use on adult mosquitoes after 6 hours of exposure

\begin{tabular}{cccc}
\hline Plantes & Equation de régression & $\begin{array}{c}\text { Coefficient de } \\
\text { corrélation linéaire }\end{array}$ & DL50 \\
\hline $\begin{array}{c}\text { Azachdirachta indica } \\
\text { (leaves) }\end{array}$ & $y=1,293 x+3,246$ & 0,99540468 & $36,1470268 \%$ \\
\hline $\begin{array}{c}\text { Boswellia dalzielii } \\
\text { (leaves) }\end{array}$ & $y=1,269 x-5,351$ & 0,98587165 & $43,6161351 \%$ \\
\hline $\begin{array}{c}\text { Boswellia dalzielii } \\
\text { (bark) }\end{array}$ & $y=1,279 x-3,160$ & 0,97512005 & $41,5615553 \%$ \\
\hline $\begin{array}{c}\text { Khaya senegalensis } \\
\text { (bark) }\end{array}$ & $y=1,038 x+6,979$ & 0,95905135 & $41,4555917 \%$ \\
\hline $\begin{array}{c}\text { Ocimum Canum } \\
\text { (leaves) }\end{array}$ & $y=1,338 x-4,580$ & 0,95890812 & $40,8003588 \%$ \\
\hline
\end{tabular}

The analysis of the different results shows that 6 hours after exposure, the powder of the leaves of Azadirachta indica has proved to be more effective with an LD50 of $36.14 \%$, followed by powder of leaves of Ocimum canum and barks of Khaya senegalensis respectively with LD50 of $40.80 \%$ and $41.45 \%$ (table 3 ).
All plant powders used Boswellia dalzielii sheets proved to be less efficient compared to others, because its LD50 is highest at $43.61 \%$ (table 3 ).

In sum, the toxic effects of each plant on adult mosquitoes depend on the plant, the dose and duration of exposure. 


\section{3-Discussion}

The LD50 for adult mosquitoes showed that among the 5 plant powders tested, two had proved interesting in terms of toxicity, namely those of Azadirachta indica and Ocimuin canum. They are in fact the lowest LD50. These results are in agreement with those of Saotoing (2005), who after studying the insecticide effect of six essential oils of plants present in the three northern regions of Cameroon, got the lowest lethal concentration 50 (LC50 = $11.9 \mathrm{mg} / \mathrm{m} 2$ ) in Ocimum canum. Similarly, Francis et al., (2009) in Littoral Cameroon, class essential oil of Ocinium canum before essential oils of Ocimum gratissimum and Thymus vulgarisin terms of insecticidal efficiency on adult mosquitoes. These different results are obtained with very low LD50 and LC50 for ours. Indeed, the essential oils extracted from the leaves, seeds or bark of plants have high concentrations of active ingredient for plant powders. It is sufficient therefore to extract a low concentration of essential oil to get satisfactory results.

Mortality rates observed in the species Ocimum canum and Khaya senegalensis 6 hours after exposure of mosquitoes at $15 \%$ and $30 \%$ dose are $21.05 \%$ and $54.55 \%$ respectively while for same plants at doses $30 \%$ and $45 \%$ for there was a decrease of mortality rate respectively $15 \%$ and $46.94 \%$. These same irregularities are also observed 24 hours after exposure of species of Boswellia dalzielii (leaves) and Khaya senegalensis where we observed only at $45 \%$ and $60 \%$ doses, the rate of mortality are declining compared to the doses $60 \%$ and $75 \%$ respectively. These irregularities could be explained by the non-homogeneity made sticks. Indeed these tubs are made from a mixture in which its homogeneity could be perfect. Thus, for a tub at a given dose, it may submitted by location of doses more or less above the desired dose.

Furthermore, the results obtained with the same sticks for 15 minutes of exposure do not exhibit these irregularities. This leads us to introduce time as a second possible cause of these irregularities. The time factor is simultaneously the duration of the experiment and the lifetime of adult mosquitoes. Indeed, toxicity tests are carried out on adult mosquitoes from one to two days of age, these tests last 24 hours; this gives us the possibility of having adult mosquitoes of 3 days of age at the end of the experiment. However the estimated useful life of the adult mosquitoes bred in the conditions of the experiment is 3 to 4 days. It could therefore have an interference between the mortality of mosquitoes due to the insecticide effect and the mortality of insect due to their short lifespan.

\section{CONCLUSION}

The use of insecticides of synthesis, more regulated for the protection of the environment, is the origin for most numerous cases of insects' resistance. In this context, the www.ijeab.com use of natural molecules (ecological and economic interest) to insecticide properties is of lesser toxicity to humans turns out be an alternative approach to the use of synthetic insecticides.

In this study, we proceeded to the formulation of the insecticide tubs on bases of four plants one found in the Far North region of Cameroon and assessing their insecticidal potential on adult mosquitoes of said region. All samples showed an interesting insecticidal activity. These natural fuel shave as advantages: availability, abundance, their efficiency, their low cost and above all less toxic to man and the environment.

The vulgarization of the virtues of these plant species in medium-term have an intermediate solution in preventing malaria control, but also in improving the production of certain foodstuffs which are major concerns for the people of the far North region of Cameroon.

We are considering as a result of the present work to clarify the nature of compounds chemicals responsible for insecticidal activity observed in the studied plants. This might be possible through a chromatographic study of essential oils extracted from leaves, bark and seeds of these plants.

\section{REFERENCES}

[1] Barbouche N., Haider B., Victoria G. and Ammar M.(2001).Contribution to the study of the biological activity of extracts of Cestrum parqui the ports leaves. (Solanaceae) locust Schistoceraca gregaria (Forsk.) .Biotechnol. Agron. Soc. 5 (2): 85-90.

[2] Brahim A., Saadia O., Fouad M. and Saadia M. (2006). Preliminary Evaluation of larvicidal activity of aqueous extracts of the leaves of castor bean (Ricinus communis 1.) and the wood of thuya (Tetraclinis articulata) on four mosquitoes culicidae larvae: Culex pipiens (Linnaeus), Aedes caspius (Pallas), Culiseta victim (Aitken) and Anopheles Maculi pennies (Meigen). Arch Pathol Lab Med. 2006 Jul; 130(2): 67-71.

[3] Brey J.D.D. (2005). Institute of Agricultural Research for Development (IRAD), Promotion: manufacturing processes and techniques for enhancing the effectiveness of insecticides made from neem seeds. Collection mémoires No. 102, Paris, 1984, $200 \mathrm{p}$.

[4] Crosby D.G. (1966). Natural pest control agents.In Gould, R.F. (Ed.).Natural Pest Control Agents. Adv. Chem. Ser. 53: 1-16.

[5] Slip D., Lee F., Viniaker H. and Bidat E. (2006). Allergic Reactions to the bites of mosquitoes, what prevention? Archives de pédiatrie, 2006 13(1):9399.

[6] Francis t., Douglas P.M.J., Sameza M.L., Nkouaya F. and Ronald F.G.B. (2009). Larvicidal activity on

Page | 1491 
Anopheles gambiae Giles and chemical composition of the essential oils extracted from four plants cultivated in Cameroon. Med. Vet. Entomol., 13 (1): 77-84.

[7] Georghiou G.P., Ariaratnam V., Pasternak M.E. and Lin C.S. (1975). Organophosphorus multidrug resistance in Culex quinquefasciatus in California. J. Econ. Entomol., 68: 461-467.

[8] Jacobson M. (1989). Botanical pesticides, past present and future In Arnason J.T. and al. (Ed.).Insecticide of plant origin. Washington, D.C.: American Chemical Society Symposium series, 387: 1-10.

[9] Saotoing P. (2005). Diversity mosquito in the northern part of Cameroon and effect of essential oils on adults of Anopheles gambiae, University of Yaoundé I Cameroon. Doctoral thesis.264 p.

[10] Sasmal G., Jilien J.L. and Gaven B. (1977). Progressive acquisition of resistance to chlorpyrifos of larvae of Culex pipiens in the South of the France. Parasitologia, 19 (1) (2): 79-94. 